\title{
As propostas políticas e epistêmicas do movimento indígena equatoriano para a construção da globalização contra-hegemônica
}

Juliane Rodrigues Teixeira ${ }^{1}$

\begin{abstract}
Resumo: Nas últimas décadas, surgiram propostas políticas e epistêmicas alternativas aos postulados hegemônicos desde alguns movimentos sociais presentes no Sul Global. É o caso das propostas feitas pelo movimento indígena equatoriano que se tornou um ator político e epistêmico cada vez mais relevante nas dinâmicas políticas e sociais do país, propondo alternativas à globalização neoliberal hegemônica. Desta maneira, busca-se refletir sobre o pensamento gerado pelo movimento indígena equatoriano, por meio do diálogo entre as Epistemologias do Sul, o pensamento decolonial latino-americano e a ontologia política relacional. Assim, por meio de uma revisão bibliográfica de autores que tratam do tema, destaca-se a importância do movimento indígena equatoriano como um ator político e epistêmico que pode inspirar na geração de alternativas viáveis a alguns problemas contemporâneos a partir das propostas de construção da globalização contra-hegemônica.
\end{abstract}

Palavras-chave: Movimento indígena equatoriano; ator político e epistêmico; Epistemologias do Sul, Pensamento decolonial latino-americano e ontologia política relacional; Globalização contra hegemônica.

\section{The political and epistemic proposals of the Ecuadorian indigenous movement for the construction of counterhegemonic globalization}

\begin{abstract}
In recent decades, alternative political and epistemic proposals have emerged against hegemonic postulates from some social movements present in the Global South. This is the case of the proposals made by the Ecuadorian indigenous movement that has become an increasingly relevant political and epistemic actor in the country's political and social dynamics, proposing alternatives to hegemonic neoliberal globalization. Thus, it reflects on the thinking generated by the Ecuadorian indigenous movement through the dialogue between Southern Epistemologies, Latin American decolonial thinking and relational political ontology. Thus, through a literature review of authors dealing with the theme, it shows the importance of the indigenous movement as a political and epistemic actor that can inspire the generation of viable alternatives to some contemporary problems, based on the proposals for the construction of counterhegemonic globalization.Traducción al Inglés.
\end{abstract}

Keywords: Ecuadorian indigenous movement; Political and epistemic actor; Epistemologies of the South; Latin American decolonial thinking and relational political ontology; Counterhegemonic globalization.

\footnotetext{
Doutoranda em Estudos Americanos, Instituto de Estudios Avanzados, Universidad de Santiago de Chile. Bolsista de doutorado nacional da Agência Nacional de Investigação e Desenvolvimento do Governo do Chile. Investigadora visitante Universidade de Coimbra. E-mail: juliane.rt@gmail.com
} 


\section{Introdução ${ }^{2}$}

Partindo da construção de outros marcos epistemológicos, ontológicos e teóricos, críticos à concepção da modernidade eurocêntrica, por meio do diálogo entre as Epistemologias dos Sul, o pensamento decolonial latino-americano e a ontologia política relacional, juntamente com a revisão bibliográfica, de caráter qualitativo, busca-se reflexionar sobre o movimento indígena equatoriano como um ator político e epistêmico importante, cujas propostas transcendem o âmbito comunitário ao passar a integrar os debates políticos, constitucionais e epistêmicos do país.

Considera-se que é um ator relevante na elaboração de propostas alternativas à globalização hegemônica neoliberal. As suas propostas, desde as bases comunitárias, incidem também na reformulação do Estado, que alguns autores consideram que contribuíram a sua refundação, a partir da construção do Estado Plurinacional como modelo alternativo ao Estado-nação moderno eurocêntrico, forma de organização estatal que predomina a nível global como consequência da expansão do pensamento moderno eurocêntrico, justamente a partir do colonialismo iniciado no continente americano.

Desta forma, primeiramente se aborda o diálogo entre as propostas epistemológicas, ontológicas e teóricas que fundamentam o presente trabalho. Posteriormente, analisa-se o movimento indígena equatoriano como ator político e epistêmico, abordando a sua formação, as suas contribuições para as discussões políticas e epistemológicas, ressaltando algumas das suas principais propostas, como a plurinacionalidade e interculturalidade; o sumak kawsay, 'buen vivir' e a tradução intercultural; e outras formas de conceber a natureza. Finalmente, realizamse considerações finais sobre os aportes do movimento indígena equatoriano à construção da globalização contra-hegemônica e aos processos de descolonização.

\section{Construindo outros marcos epistêmicos por meio do diálogo entre as Epistemologias do Sul, o pensamento decolonial latino-americano e a ontologia política relacional}

As Epistemologias do Sul buscam a pluralização do conhecimento por meio da introdução do conhecimento historicamente rejeitado pelo Norte Global, amparado pela hegemonia do conhecimento científico moderno e eurocêntrico. Neste sentido, destaca a existência de propostas contra-hegemônicas elaboradas pelas práticas, lutas e resistências dos movimentos sociais do Sul Global, como é o caso das práticas que surgem desde a América Latina. Dessa forma, busca-se validar o conhecimento produzido por grupos marginalizados pela intersecção da matriz capitalista, colonial e patriarcal por meio de perspectivas dos próprios atores que lutam contra a esses mecanismos de dominação.

Propõem a existência de uma linha que divide o mundo, invisibilizando os modos de vida e de geração de conhecimento existentes no 'outro lado da linha', que Boaventura de Souza Santos (2010a) chama de 'linha abissal'. Essa linha simboliza a divisão do mundo entre

2 Este trabalho faz parte da investigação doutoral "L emergencia indígena y su incidencia en el pensamiento internacional latinoamericano. Los casos de Ecuador y Bolivia en principios del siglo XXT". 
o mundo moderno e o não moderno; entre o ocidental e o não ocidental; entre a razão e a emoção; e entre os seres humanos e a natureza, mantendo a existência de lógicas coloniais do 'outro lado da linha'. Destaca-se, portanto, a natureza abissal do pensamento eurocêntrico, devido ao seu caráter excludente.

Desse modo, as Epistemologias do Sul buscam tornar visíveis as experiências encontradas no 'outro lado da linha abissal', por meio da sociologia de emergências que compreende as experiências ocultadas ou produzidas como inexistentes pela ciência eurocêntrica e pela sociologia das ausências. Desde esta última, considera-se que o que não existe é intencionalmente produzido como inexistente devido à baixa credibilidade atribuída aos sujeitos epistêmicos que não são considerados sujeitos capazes de produzir conhecimento viável por não estarem enquadrados nos métodos racionais que dominam a ciência moderna eurocêntrica (SANTOS, 2010a).

Assim, a sociologia das ausências atribui importância aos elementos negados e ignorados, construídos como inexistentes, por meio da sociologia das emergências que considera as propostas de movimentos sociais - como o movimento indígena - alternativas concretas e viáveis a alguns problemas atuais. Dessa forma, as Epistemologias do Sul contribuem para a valorização de outros projetos de construção do conhecimento que vêm das práticas cotidianas e das lutas e resistências das vítimas do colonialismo que persiste até hoje por meio dos mecanismos de colonialidade existentes em diversos campos.

Essa abordagem dialoga com a perspectiva decolonial latino-americana que considera que a colonialidade vai além da duração do colonialismo como um período histórico, o que possibilita compreender a continuação das formas coloniais de dominação mantidas pelas estruturas de poder em diversos níveis, como por meio da colonialidade do poder econômico e político; e pela colonialidade do ser, do gênero e a colonialidade do saber (GROSFOGUEL, 2010).

Precisamente, a colonialidade começa com o padrão de poder colonial ligado ao processo de acumulação capitalista a partir da conquista da América. Foi posteriormente articulada com a hierarquia racial e étnica a nível global, gerando classificações binárias entre povos superiores e inferiores, bárbaros e civilizados, desenvolvidos e subdesenvolvidos que permanecem na atual fase da globalização. Assim, desde a perspectiva decolonial, a noção de 'raça' foi o eixo fundamental na formação do novo padrão global de poder, transformando-a na base para a construção do poder, hegemonia e dominação mundial europeia junto ao colonialismo e imperialismo, classificando a população mundial de acordo com essa ideia. Essa classificação gerou diferenças e hierarquias que permanecem no nosso cotidiano, transformando alguns grupos em subalternos, como é justamente o caso dos indígenas (QUIJANO, 2000).

O pensamento decolonial latino-americano destaca a ideia de que a formação histórica do capitalismo está intrinsecamente associada ao colonialismo. Dessa forma, a colonialidade do poder resulta de modos de articulação de poder e da configuração do capitalismo em conjunto com a hegemonia europeia. É uma matriz de poder global que controla diversas áreas, como subjetividades e formas de produção do conhecimento. Também se mostra em instituições, como o Estado-nação. Assim, a partir da visão decolonial da história latino-americana, a independência dos Estados-nações da região pode ser interpretada como a continuação do 
sistema colonial que invisibilizou e buscou destruir as formas de organização coletiva dos povos originários do continente, o que historicamente motivou as lutas deste setor (LLASAG, 2017).

Então, a partir do pensamento decolonial, em diálogo com as Epistemologias do Sul, propõe-se que a linha abissal exclui realidades consideradas irrelevantes pelo pensamento hegemônico, geradas pela colonialidade do ser e do saber que transformam em irrelevantes os conhecimentos produzidos pelos setores populares. Dessa forma, as lutas sociais surgem como forma de romper com essas linhas abissais por meio das resistências políticas e epistemológicas, inserindo elementos de transformação na ordem social próprias de alguns grupos, como é o caso do movimento indígena (SANTOS, 2010a).

Precisamente, a partir dessas abordagens epistemológicas, são recuperadas outras formas de geração de conhecimento historicamente marginalizadas e invisibilizadas, reconhecendo a diversidade epistemológica existente no mundo, construindo alternativas válidas aos postulados hegemônicos. Outras formas de produção do conhecimento são legitimadas a partir de práticas, resgatando paradigmas alternativos ao positivismo e racionalismo da ciência moderna eurocêntrica que trata o conhecimento como um saber objetivo e neutro, ocultando a sua associação com a evolução do capitalismo, bem como sua universalização junto aos processos de colonialismo e de imperialismo europeu (MENESES; PEIXOTO, 2018).

Dessa forma, as Epistemologias do Sul buscam resgatar o conhecimento construído a partir da herança colonial destacado pelos postulados decolonias, construindo alternativas para superá-las por meio de projetos populares, visibilizando outros saberes que contribuem a transformar a realidade a partir das perspectivas subalternas que foram deixadas de lado pelo mundo moderno, colonial, capitalista e patriarcal, rompendo com a imposição epistemológica.

Assim, transforma as experiências ausentes em experiências presentes por meio do processo de tradução intercultural entre as diferentes experiências, construindo novos conceitos que são elaborados em espaços e tempos distintos. Articula o conhecimento científico com outras formas de conhecimentos por meio da interculturalidade, construindo uma ecologia dos saberes a partir do diálogo do conhecimento entre a academia e os movimentos sociais. Consequentemente, a tradução intercultural se torna uma ferramenta essencial para o diálogo com as diversas experiências existentes no mundo, contribuindo para a ecologia dos saberes como forma de questionar a colonialidade do saber que abre espaços para uma maior pluralidade epistêmica (MENESES; PEIXOTO, 2018).

Por meio da ecologia dos saberes se busca substituir o modo de conhecimento singular desenvolvido pelo conhecimento eurocêntrico, integrando outras concepções sobre o tempo, espaço, conceitos como poder, construção do Estado-nação, entre outros. Combina formas de conhecimento ancestral, um conhecimento acumulado ao longo de gerações de forma preponderantemente oral, com o conhecimento científico moderno, levando à complementaridade entre o conhecimento ancestral e o conhecimento científico moderno.

Observa-se, assim, que a interculturalidade contribui para a compreensão das diferentes experiências que são levadas a cabo no mundo, destacando o seu caráter de possibilidade concreta, por meio da sociologia das emergências. O diálogo intercultural pode ressaltar os 
saberes que emerge das lutas sociais como forma de descolonizar a sua produção. Dessa forma, nos depararíamos com a produção de conhecimentos que transcendem a epistemologia moderna eurocêntrica, desenvolvida principalmente em universidades e centros de pesquisas acadêmicas, transcendendo os modelos racionalistas (MENESES; PEIXOTO, 2018).

Portanto, ao propor resgatar outras formas de ser, estar, ver e conceber o mundo e gerar conhecimentos, as Epistemologias do Sul também contribuem a resgatar outras ontologias, conectado à política ontológica que questiona as explicações cartesianas sobre o conhecimento científico. Assim, juntamente com as abordagens decoloniais e as Epistemologias do Sul, acrescenta-se a ontologia política relacional que ajuda a visibilizar aspectos geralmente ignorados pelo conhecimento hegemônico, de forma a transcender os dualismos e separações existentes na racionalidade moderna, problematizando as separações entre natureza, sociedade e cultura (ESCOBAR, 2018).

A ontologia política relacional transcende o antropocentrismo e o eurocentrismo que domina as ciências sociais com abordagens elaboradas desde o Sul Global, questionando a ontologia e a epistemologia dominante ao destacar a existência do pluriverso (ESCOBAR, 2018). Neste caso, o Sul Global transcende a localização geográfica, compreendendo o espaço geopolítico formado por todos os grupos humanos, países e regiões historicamente sujeitas aos sistemas de opressão e exclusão gerados pelas intersecções das matrizes capitalistas, coloniais e patriarcais dispersadas por meio do processo de colonização europeia iniciado no século XV com a colonização de Abya Ayala, ou seja, a partir da colonização do continente americano (MENESES; PEIXOTO, 2018).

Vale a pena notar a necessidade de transitar da ontologia hegemônica moderna e eurocêntrica que considera apenas a existência de um mundo, para a concepção do pluriverso, que ressalta a existência de outras racionalidades, outras formas de ser, estar e conhecer o mundo. Está vinculada como o encontro do mundo social e do mundo natural que contribui para a reconstrução dos mundos locais silenciados pela sociologia das ausências, como consequência da colonialidade do saber (ESCOBAR, 2018).

O pluriverso compreende a convivência de vários mundos que buscam resistir à globalização hegemônica neoliberal, como por meio das lutas dos movimentos sociais que também podem ser consideradas lutas ontológicas, reinserindo a diversidade existente no mundo, ocultada pela construção do mundo singular e fundamentada pelo pensamento eurocêntrico. Assim, procede com a problematização da hegemonia e exclusividade atribuída ao conhecimento científico moderno e eurocêntrico como única forma válida de produção de conhecimento, tornando visível a existência de outras formas que contribuam para a transformação da sociedade, recuperando o conhecimento associado às lutas sociais que ocorrem em diferentes espaços e tempos.

Isso ocorre por meio da introdução de outras abordagens ontológicas e epistemológicas, de corte crítico, complementando, assim, o pensamento latino-americano. Neste sentido, enquadram-se as propostas do movimento indígena que buscam romper com os dualismos ontológicos tradicionais entre natureza, sociedade e cultura presentes na racionalidade moderna. 
Consequentemente, a incorporação de teorias que possibilitam a transformação social é a base das Epistemologias do Sul, ajudando a repensar a realidade desde outros pontos de vistas, especialmente a partir de experiências que não são corretamente traduzidas pelo conhecimento científico moderno e eurocêntrico. Assim, busca-se a transição ao pluriverso a partir do resgate de formas invisibilizadas de conhecimento, junto a justiça cognitiva proposta por esses modelos epistemológicos, ontológicos e teóricos.

\section{Analisando o caso específico: $O$ movimento indígena equatoriano como ator político e epistêmico}

Destacam-se importantes acontecimentos políticos que são normalmente marginalizados pela produção acadêmica hegemônica, como os levantamentos indígenas que levaram a mudanças políticas a partir das lutas pela emancipação. De fato, ressalta-se o protagonismo deste setor na América Latina, principalmente em países como Equador e Bolívia, atuando inclusive na refundação dos Estados ao introduzirem algumas das suas propostas nos textos constitucionais, contribuindo para a construção do Estado plurinacional na região, gerando estratégias mais amplas de mudança social para romper com o modelo tradicional de formação de identidades nacionais que negam a existência de identidades distintas por meio da violência étnica, cultural, social, política e epistêmica.

Neste sentido, a partir das epistemologias e ontologias próprias, o movimento indígena problematiza a concepção linear do tempo, buscando no passado características para a construção do futuro. Questiona a essência do Estado capitalista, neocolonial e hierárquico, propondo, em vez disso, a plurinacionalidade como outro modelo de organização que visa ser mais democrático e horizontal, integrando concepções que apontam para outras lógicas anticapitalistas e anticoloniais (LLASAG, 2017).

De fato, pode ser considerado como um dos principais atores da região que tem contribuído para a construção de alternativas e novas elites em alguns países, como em Equador e Bolívia. Além de destacar a democracia comunitária, contribui para a introdução de outras formas de conceber as relações entre seres humanos, sociedades e natureza a partir de outras racionalidades econômicas, problematizando e propondo alternativas à hegemonia da racionalidade econômica moderna eurocêntrica que nos leva a crises multidimensional que vivenciamos a nível global.

Alguns autores destacam a 'desobediência epistêmica' do movimento indígena na construção de seu pensamento político. A 'desobediência epistêmica' estaria associada à 'desobediência política' materializada nas formas de resistências históricas - como são os levantamentos indígenas - e as tentativas de construir a autonomia e a autodeterminação. O conceito, profundamente desenvolvido por Walter Mignolo (2017), é fundamental para o projeto decolonial, questionando os postulados políticos e epistêmicos dominantes.

Essa 'desobediência política e epistêmica' está associada às propostas contra-hegemônicas elaboradas pelo movimento indígena. Questionam a matriz epistemológica da produção do capitalismo que limita espaços para a interculturalidade e reduz a luta dos povos indígenas 
à luta pela terra, limitando-os epistemologicamente à qualidade de camponeses. Assim, este setor problematiza o modelo de conhecimento desenvolvido pelo Ocidente que intervém na elaboração do conhecimento próprio indígena por meio do colonialismo, buscando reconstruir os seus saberes na medida em que se torna um ator político e epistêmico cada vez mais relevante (DÁVALOS, 2002).

Consequentemente, problematiza o âmbito epistemológico ao destacar as relações de poder. Enfatiza que a construção do conhecimento está inserida nas lógicas, estruturas e relações de poder e dominação, portanto, não é neutro conforme é proposto pelo conhecimento científico moderno. Assim, os questionamentos do movimento indígena estão associados ao pensamento decolonial que propõe que o conhecimento está relacionado às construções históricas e 'geo-localizadas', tanto 'geo-politicamente' - dependendo do lócus da enunciação - como 'corpo-politicamente' - dependendo da subjetividade dos sujeitos que constroem esses conhecimentos (MIGNOLO, 2017).

Estas propostas podem ser analisadas pelas Epistemologias do Sul, ao tratar de temas vinculados ao debate civilizacional a partir dos próprios sistemas de vida desse setor. Além disso, por meio dos mecanismos de autodeterminação, problematiza os conceitos hegemônicos na busca de alternativas ao sistema liberal (SANTOS, 2010b). Assim, desde essas perspectivas, o movimento indígena propõe a construção de um conhecimento não eurocêntrico a partir das heranças coloniais ainda presentes na América Latina, tornando-se um 'paradigma outro' condicionado justamente pela diferença colonial, em que se destaca a importância do conhecimento ancestral e a recuperação desses saberes como alternativas viáveis por meio da sociologia das emergências.

Além disso, está associada às ontologias políticas relacionais como uma das bases dos mundos indígenas, constantemente presentes nas suas lutas, especialmente nas lutas territoriais, defendendo também os seus mundos relacionais. Neste sentido, as ontologias relacionais se vinculam com o conjunto de práticas e interações entre diversos seres, humanos, animais, espirituais, essenciais para os territórios e as comunidades indígenas. Essas práticas se opõem ao mundo singular ligado ao capitalismo que transforma tudo em mercadoria, reduzindo a existência de outros mundos à supremacia do capital (ESCOBAR, 2018).

Assim, destaca-se a reorientação epistemológica e ontológica relacional, de caráter não dualista, contribuindo para a crítica à ontologia racionalista e ao giro ontológico por meio da política epistêmica e da política de relacionalidade que evidenciam a existência de outros sistemas de vida e de outras formas de gerar conhecimentos. Dessa forma, o movimento indígena tem buscado confrontar poderes hegemônicos desde a esfera política, mas também desde o domínio do conhecimento, ao vinculá-lo às ações políticas, à interculturalidade e às lutas históricas contra os sistemas de dominação e exploração. 


\section{A formação do movimento indígena equatoriano}

É importante destacar a trajetória do movimento indígena, desenvolvendo estratégias para a construção do poder contra-hegemônico, como o fim de alcançar as suas reivindicações ao longo da história colonial e republicana, resgatando os postulados que foram intervindos pelo colonialismo. No caso equatoriano, destacam-se as lutas históricas para destruir os sistemas de 'haciendas', propriedades oligárquicas que se constituíam como as bases das estruturas fundiárias e sociais do país, em que predominavam as relações de poder e dominação sobre os povos indígenas desde diversos âmbitos, econômico, político, cultural, epistêmico e simbólico, associados aos mecanismos da colonialidade do poder, do ser e do saber. Assim, as 'haciendas' foram espaços históricos de geração do conhecimento do movimento indígena por meio das lutas e resistências até a sua extinção, nos anos 1990 (DÁVALOS, 2002).

Eram o principal eixo econômico durante grande parte do período republicano; base do poder político e econômico do Equador. Mais do que relações de dominação e subordinação, essas propriedades fundiárias também eram espaços de encontros entre o mundo andino e o mundo ocidental, espaços de conflito, repressão e violência, formando um sistema de servidão. Mas, acima de tudo, também eram espaços de resistências e mobilizações que exerciam grande influência sobre o imaginário emancipatório do movimento indígena que vinha se organizando desde a década de 1920 (DÁVALOS, 2002).

Nestes espaços predominavam o privilégio epistêmico e a colonialidade do saber, uma vez que os indígenas não tinham acesso à educação, pois isso poderia comprometer a dominação sobre eles. Portanto, o controle da produção de conhecimento seria uma forma de subjugálos, o que contribuiu para transformar a luta pela educação como uma constante do setor indígena equatoriano desde a década de 1940 como forma de alcançar a sua emancipação. Assim, destaca-se a luta histórica pela educação, proibida pelo sistema de 'haciendas' que prevaleceu na organização agrícola e oligárquica até poucas décadas atrás.

A formação de sindicatos agrícolas indígenas no país se dá a partir da década de 1920, vinculada, inicialmente, à lógica da classe social, tornando-se a base para a construção das futuras organizações indígenas. Até 1960, foram criados vários sindicatos e organizações indígenas no Equador. Entretanto, o movimento indígena equatoriano conseguiu resgatar e organizar as suas estruturas epistemológicas próprias, distanciando-se progressivamente da categoria de campesinos a partir da elaboração de um novo campo epistemológico para apoiar suas lutas políticas e sociais, ressaltando elementos como cultura e territorialidade na construção de conceitos como a interculturalidade e a plurinacionalidade. Estas se tornaram importantes categorias epistêmicas à medida que o movimento se torna um ator político cada vez mais relevante no país. Assim, destaca-se o trânsito da figura do camponês para o resgate da identidade indígena intensificada ao longo das últimas décadas (DÁVALOS, 2002).

Como resultado, as mudanças na percepção de assimilação e integração subordinadas ao Estado-nação geraram propostas de integração que passaram a exigir o reconhecimento da pluriculturalidade existente no país por meio das práticas de interculturalidade. Precisamente, é importante destacar as relações entre etnia e classe social, associadas às correlações de 
dominação e subordinação existentes entre culturas, juntamente à distribuição desigual dos recursos como resultado do período colonial. A etnia está associada à diversidade, o que leva à busca pelo reconhecimento da diversidade e não da igualdade almejada no caso das classes sociais, ideia presente especialmente no pensamento marxista. Apesar das diferenças, é evidente as relações entre etnia e classe social (ALBÓ; BARRIOS SUVELZA, 2007).

Dessa forma, o movimento indígena equatoriano deixa progressivamente de depender da representação dos partidos de esquerda, construindo a sua própria representação política ao elaborar as suas próprias estratégias para alcançar suas demandas de autonomia. Essas propostas são de natureza anticapitalista e anticolonial que transcendem as demandas tradicionais dos setores camponês e proletário, destacando aspectos da autonomia cultural e da autodeterminação territorial e do pleno exercício de seus modos de vida.

Nesse sentido, há a criação do ECUARUNARI (Ecuador Runakunapak Rikcharimuy em Kichwa, que significa Movimiento de Indígenas e Campesinos do Equador, da nacionalidade Kichwa), em 1972, como uma organização da nacionalidade Kichwa da serra equatoriana, simbolizando o despertar desses povos. Em seguida, a realização do primeiro congresso regional de nacionalidades indígenas da Amazônia equatoriana levou à criação da CONFENAIE (Confederação das Nacionalidades Indígenas da Amazonia Equatoriana), em 1980, no contexto de aumento da colonização e do ingresso de transnacionais petroleiras na região; posteriormente, ocorre a criação do CONAICE (Confederação de Nacionalidades e Povos Indígenas da Costa Equatoriana), reunindo as nacionalidades indígenas da costa equatoriana. Isso levou à construção da CONAIE (Confederação das Nacionalidades Indígenas do Equador), a Confederação de Nacionalidades Indígenas do Equador, em 1986, reunindo todas as organizações regionais no seu interior (LLASAG, 2017).

A fundação da CONAIE é um elemento importante na consolidação da proposta de construção do Estado plurinacional a partir dos anos 1980 que se torna uma demanda importante no fortalecimento progressivo da organização. É resultado do projeto de unidade das organizações regionais de camponeses e indígenas, englobando as suas demandas acumuladas ao longo da história colonial e republicana.

É precisamente a partir deste momento que o movimento indígena contribui com a introdução de outras concepções de terra e território que transcendem o espaço físico, ao considerá-lo como um espaço em que a vida é gerada e reproduzida em toda a sua integralidade, mas que foi intervindo e despojado pelo sistema colonial, processo que segue por meio dos mecanismos de colonialidade do poder, do ser e do saber presentes até a atualidade. Assim, o movimento indígena tem contribuído para a expansão do conceito de território, expandindo-o para englobar seus próprios sistemas de vida por meio do fortalecimento da comunidade e do resgate do pensamento próprio. O discurso é ampliado, gerando um novo sentido político aos levantamentos indígenas.

Assim, passou a questionar, com maior veemência, o modelo excludente e neocolonial do Estado-nação, juntamente com suas estruturas hierárquicas; o sistema de educação hegemônica; assim como o sistema capitalista e extrativista cada vez mais predatório da natureza, que 
reproduz estruturas neocoloniais no âmbito internacional, clamando por direitos coletivos, territoriais, autonomia e autodeterminação. Por outro lado, propõe a valorização dos elementos próprios, fortalecendo as estruturas comunitárias, ocupando os levantamentos indígenas desde as comunidades, alcançando o âmbito nacional como uma das principais estratégias de ação política, especialmente a partir de 1990 (LLASAG, 2017).

Neste sentido, merece destaque o levantamento indígena de 1990, realizado pela CONAIE, buscando a legalização e a recuperação das terras diante da relutância do Estado em atender às demandas deste setor. $\mathrm{Na}$ verdade, esta foi a primeira revolta indígena de caráter nacional no Equador, introduzindo essa estratégia que passou a ser ocupada, a nível nacional, nas lutas do movimento indígena contra as propostas neoliberais dos governos de turno. Esses levantamentos seguem até a atualidade, como bem demostrou o ocorrido no recente levantamento indígena de outubro de 2019, organizado pela CONAIE junto com outros setores sociais contra as propostas neoliberais do governo de Lenin Moreno.

As demandas pela construção da autonomia territorial estiveram presentes principalmente nos levantamentos indígenas de 1990, 1992 e 1994 ocorridos no país, reivindicando a construção do Estado plurinacional. De fato, destaca-se a legalização das terras amazônicas intensificada após a marcha da Amazônia em direção a Quito, em 1992. Nesta marcha, exigindo a concessão de territórios e o reconhecimento do Estado plurinacional, intensificam-se as demandas por autonomia na região amazônica, incluindo autonomia para decidir sobre a exploração dos recursos naturais existentes nos territórios dos povos e nacionalidades indígenas amazônicos (CRUZ RODRÍGUEZ, 2012).

Assim, a relevância do movimento indígena, que aumentou desde o levantamento indígena de 1990, culminou no projeto de construção do Estado plurinacional, posteriormente incorporado na Constituição de 2008, intensificando a sua atuação como ator político e epistêmico importante no país ao exercer influência na institucionalidade do Estado, ao mesmo tempo que busca fortalecer as suas bases comunitárias.

\section{Contribuições do movimento indígena equatoriano para as discussões políticas e epistemológicas}

Foram várias as tentativas de eliminar os saberes e as memórias dos povos ancestrais. No entanto, é importante destacar a resistência por meio de lutas políticas, sociais e a recuperação da memória histórica e dos sistemas de vida próprios dos povos e nacionalidades indígenas do Equador. Assim, destaca-se a grande capacidade de luta e resistência do movimento indígena, contribuindo para a elaboração de conceitos importantes que têm incidência nos debates políticos e epistêmicos, como a plurinacionalidade, a interculturalidade, o sumak kawsay e a natureza como sujeito de direitos, por exemplo, analisados a continuação.

Neste sentido, os últimos processos constitucionais realizados no Equador e na Bolívia estão associados às lógicas de luta dos movimentos sociais, especialmente do movimento indígena, mostrando a existência de outros paradigmas não eurocêntricos, junto a sua maior proeminência política. Desta maneira, destaca-se a plurinacionalidade que introduz novas 
lógicas epistemológicas e políticas e a interculturalidade que visa à igualdade entre as culturas, buscando romper com as hierarquias e inferiorizações atribuídas às culturas dos povos e nacionalidades indígenas, além do sumak kawsay que propõe o resgate dos seus sistemas próprios de vida (SANTOS, 2010b).

\section{A plurinacionalidade e a interculturalidade}

A plurinacionalidade pode ser definida como o traço de identidades diferenciadas presentes no interior da nação, que passam a ser constitucionalmente reconhecidas; a interculturalidade pode ser considerada como um modo de conectar várias formas culturais, que transcendem as identidades e interesses dos grupos; e a autonomia como um fenômeno estatal no qual um espaço sociopolítico possui a capacidade de decidir sobre seus temas, estabelecidos pela constituição, vinculados a uma visão policêntrica de distribuição de poder (ALBÓ; BARRIOS SUVELZA, 2007).

Estão associadas às reivindicações históricas do movimento indígena, buscando o reconhecimento de sua diversidade cultural e sistemas de vida, sem a fragmentação do Estado, uma vez que a construção da plurinacionalidade proposta por esse setor foi inicialmente considerada uma ameaça à integralidade do Estado. Portanto, é um novo modelo de Estado que reconhece as demandas históricas desses coletivos, mantendo sua unidade (CRUZ RODRÍGUEZ; GUERRA URREGO, 2010).

Precisamente, a plurinacionalidade transforma a institucionalidade tradicional do moderno Estado-nação eurocêntrico, conferindo maior autonomia e direitos coletivos aos povos e nacionalidades indígenas sobre os seus territórios e os recursos naturais aí presentes. Assim, seria um modelo contemporâneo de organização política que surge desde a América Latina, reconhecendo a autonomia dos povos e as nacionalidades indígenas, o que contribui para o processo de emancipação desses grupos tradicionalmente excluídos dos espaços políticos por séculos na região, associados às suas lutas históricas (BERNAL-MEZA, 2016).

Assim, a proposta do movimento indígena reconhece a existência de outros conceitos fundamentais ligados à relevância étnica e cultural, integrando esses setores marginalizados; contribui para a modificação de conceitos tradicionais como a soberania; também articula outras concepções econômicas, políticas, sociais, culturais e epistemológicas. Assim, o Estado plurinacional amplia a concepção da nação, integrando os povos indígenas, ao mesmo tempo que lhes permite manterem as suas diversidades (ALBÓ; BARRIOS SUVELZA, 2007).

De tal forma que reconhece a diversidade de povos e culturas que compõem o Estado a partir de um novo desenho institucional que permita o pluralismo linguístico; o pluralismo jurídico, atribuindo direitos aos povos e nacionalidades para construir seus próprios sistemas jurídicos, apoiados por princípios, valores e práticas que não necessitam estar positivados; reconhece o pluralismo econômico baseado em modelos alternativos ao capitalismo hegemônico; destacam as relações dos seres humanos e da natureza, de corte comunitário, questionando o consumismo e o individualismo; propõe o combate à pobreza e à exclusão social por meio da redistribuição justa da riqueza e dos excedentes econômicos; e reconhece o pluralismo epistemológico, diversificando formas de pensamento que questionam o pensamento universal eurocêntrico. 
Portanto, a construção do Estado plurinacional pode ser vista como uma perspectiva transformadora a partir das Epistemologias do Sul por estar associada à construção de projetos populares para transformar categorias tradicionais, como o Estado-nação, a partir das ações dos movimentos sociais. O seu caráter transformador foi moldado a partir do sujeito político e social de natureza coletiva, buscando a construção de novas hegemonias na região (SILVA JÚNIOR, 2014).

Da mesma forma, o movimento indígena propõe a interculturalidade para contrapor a dominação cultural e epistêmica eurocêntrica. Está ligada às disputas sobre a construção de conhecimentos e às relações de poder, enquanto a plurinacionalidade contribui para a problematização da construção epistemológica do Estado-nação moderno eurocêntrico.

Neste sentido, destaca-se a importância da interculturalidade proposta pela CONAIE, enfatizando a necessidade de recuperar seu próprio conhecimento como base para a construção do poder, um modelo de poder também próprio que transcende o nível comunitário, tornandose, ao longo dos anos, um contrapoder frente ao Estado. Assim, a interculturalidade é um dos elementos centrais nos seus discursos, primeiro buscando acesso ao conhecimento e, posteriormente, questionando a forma da produção hegemônica e as relações de poder e dominação que têm sido mantidas, limitando o acesso ao conhecimento, mas sobretudo às formas que limitam o acesso ao conhecimento do mundo indígena. Destaca-se, portanto, o caráter político e social presente na construção da interculturalidade (DÁVALOS, 2002).

A materialização da interculturalidade está no reconhecimento do acesso à educação, mas não à educação normal e sim à educação intercultural bilíngue, buscando desconstruir os discursos teóricos e epistêmicos dominantes. De fato, destacam-se os discursos do movimento indígena que vão contra aos postulados dominantes da globalização neoliberal que busca a homogeneização das sociedades e das culturas.

\section{O sumak kawsay, 'buen vivir' e tradução intercultural}

O sumak kansay pode ser considerado um sistema de vida no qual está destacada as formas de interconexão e interdependência entre todas as formas de vida existentes em um determinado território. Está associado ao modelo de desenvolvimento próprio de comunidades indígenas que não geram grandes impactos sobre a natureza, ao contrário do que ocorre no modelo de desenvolvimento sob lógicas capitalistas. Assim, visa fortalecer a economia de acordo com a realidade das próprias comunidades, levando em consideração a importância da interculturalidade (LLASAG, 2017).

Compreende a visão de mundo de diversos povos originários de Abya Ayala, ou seja, do que hoje é América Latina, incorporando os valores que compõem a existência individual e coletiva desses grupos, associados à vida em harmonia, especialmente em relação com o ambiente natural. Assim, ressalta a existência de realidades distintas do modelo hegemônico que predomina na civilização ocidental, o que possibilita avançar em direção ao pluriverso. Neste sentido, desde estes paradigmas, os seres humanos, bem como a natureza e os outros seres que a compõem, como animais, florestas, montanhas, rios, entre outros, são considerados 
corpos dotados de razão, espírito, poder, intencionalidade e capacidade de agência (PUEBLO ORIGINARIO KICHWA DE SARAYAKU, 2009).

Estes conhecimentos e sistemas de vida foram e continuam a ser intervindos pelas diversas formas de colonialidades que existem, como a colonialidade do poder, do ser, do saber e da natureza. Além disso, foram objetos de construção de ausências na edificação do mundo singular realizada pela racionalidade moderna eurocêntrica. Assim, o surgimento do pluriverso se dá por meio de projetos políticos visíveis no Sul Global, de natureza contra-hegemônica, como alternativas para a transição civilizatória por meio de propostas que apontam a uma maior conexão dos seres humanos com a natureza, como é o caso das propostas do sumak kawsay (ESCOBAR, 2018).

Precisamente, é construído a partir do território, espaço onde a vida e o conhecimento são gerados e reproduzidos. Portanto, é evidente a importância dos conhecimentos também incorporados na educação intercultural bilíngue, resgatando seus saberes próprios, bem como a organização política e social de caráter ancestral, e a existência da organização econômica própria, de base comunitária e solidária, para a construção do sumak kanssay. Está relacionado ao território limpo, livre de poluição, juntamente ao exercício da autonomia e da autodeterminação por parte dos povos e nacionalidades indígenas, o que compõe a construção da plurinacionalidade (GUALINGA, 2020).

Assim, é uma proposta que busca a construção de um horizonte emancipatório associando o passado, ao recuperar e integrar o conhecimento ancestral; o presente, ao buscar a satisfação das necessidades, de modo racional; e o futuro, ao preservar o ambiente natural para as gerações futuras. Desloca as bases hegemônicas, como a acumulação econômica infinita que se dá pela exploração dos recursos naturais, considerada como um elemento fundamental para o modelo da vida ocidental, razão pela qual defende a natureza e propõe outros sistemas de vida associados à maior harmonia com o mundo natural (SVAMPA, 2011).

Desta maneira, está relacionado com as propostas alternativas críveis ao modelo hegemônico que emergem dos movimentos sociais no século XXI, proposições que não partem do crescimento econômico, embora possam permiti-lo. Estão apoiadas nos princípios da reciprocidade, da complementaridade e da satisfação das necessidades básicas. Precisamente, ao se inspirarem nas visões de mundo e nas experiências dos povos originais de América Latina, distanciam-se das lógicas de consumo e dos padrões de vida e do acúmulo ocidental dominantes (MENESES; PEIXOTO, 2018).

Destaca-se que esse conceito foi incorporado à Constituição do país em 2008, associado ao longo processo histórico de lutas e demandas sociais, traduzido em 'buen vivir'. As discussões sobre esse conceito se intensificaram durante a segunda década do século XXI, destacando a importância das traduções das propostas construídas pelo setor indígena, influenciando o pensamento político latino-americano, como uma característica importante ligada ao resgate de suas próprias identidades culturais (BERNAL-MEZA, 2016).

Entretanto, cabe mencionar as tensões entre a concepção do sumak kawsay, o movimento indígena, a tradução para o 'buen vivir' e o projeto desenvolvimentista do governo de Rafael 
Correa. Assim, observam-se as dificuldades de traduzir conceitos que não encontram correspondência exata em outras línguas, tornando seus significados mais amplos. É precisamente o que aconteceu com as traduções de sumak, kawsay e sumaq qamaña para 'buen vivir', presente na Constituição do Equador, e 'vivir bien', presente na Constituição da Bolívia.

Por trás desses problemas de tradução também estão as disputas políticas sobre seus significados entre os diferentes atores e o movimento indígena, este último buscando destacar os laços com seus sistemas próprios de vida. Dessa forma, o sumak kawsay para o Estado, traduzido em 'buen vivir', está associado a uma concepção diferente do que é proposto pelos povos e nacionalidades indígenas do Equador, sendo redefinido para atender às necessidades de toda a sociedade, especialmente as materiais, mantendo o modelo de desenvolvimento do país associado à exploração da natureza (LLASAG, 2017). Dessa forma, os governos progressistas reduziram a importância da sumak kawsay à redistribuição dos benefícios do desenvolvimento, apoiados, predominantemente, em atividades extrativistas, mantendo suas diversas estruturas de colonialidade, opostas às propostas dos setores indígenas (SIMBAÑA, 2011).

Mesmo com a existência de alguns elementos em comum entre o movimento indígena e o governo de Rafael Correa - como as propostas para a realização da assembleia constituinte, a construção do Estado plurinacional e discursos contra o neoliberalismo e contra os acordos de livre comércio, por exemplo -, os principais conflitos estiveram associados ao campo epistemológico, como as diferenças entre as temporalidades; entre a concepção do tempo linear que destaca a ideia de progresso, que é distinta da concepção de tempo dos povos e nacionalidades indígenas; assim como a importância atribuída à natureza na concepção de desenvolvimento racionalista, que se difere dos sistemas de vida relacionais indígenas (SANTOS, 2010b).

Dessa forma, o 'buen vivir', cujo significado foi atribuído pela institucionalidade do Estado, apresenta lógicas epistemológicas e ontológicas distintas do sumak kansay proposto pelo movimento indígena. Associado às práticas milenares, seu significado transcende a tradução para o 'buen vivir' que é a forma mais ocupada também nos debates acadêmicos, especialmente no campo da sociologia do desenvolvimento. Esses debates contribuem para ocultar os desenvolvimentos teóricos do conceito associados às práticas nas comunidades dos povos e das nacionalidades indígenas, de onde vêm essas propostas (LLASAG, 2017).

Assim, o sumak kawsay não é apenas uma teoria, já que está intrinsecamente associada à prática cotidiana das comunidades indígenas, construindo um sistema que corresponde a outro modelo, com lógicas e práticas diferentes das hegemônicas que podem ser resgatadas pelo mundo acadêmico por meio das Epistemologias do Sul, tornando visíveis os saberes e as realidades ocultadas pelo conhecimento científico hegemônico a partir das práticas cotidianas dos grupos sociais. Destaca a necessidade de ocupar a tradução intercultural presente na ecologia dos saberes como forma de construir alternativas à racionalidade moderna eurocêntrica sem alterar profundamente as bases epistemológicas originais dessas propostas. 


\section{Outras formas de conceber a natureza}

Um dos elementos centrais que caracteriza a filosofia ocidental é a concepção do ser humano como um ser separado da natureza, considerando como civilizadas as sociedades que estão separadas e distantes da natureza. Dessa forma, a sua concepção hegemônica foi estruturada em contraste com os seres humanos e os civilizados, legitimando o seu controle ao ser considerada essencialmente como fonte de riquezas e lucros. Por outra parte, destacase a existência de outras concepções que concebem a sociedade e a natureza como um todo, como no caso dos povos indígenas, já que não consideram a natureza como um recurso, mas como a responsável pela existência da vida na sua dimensão integral (SIMBAÑA, 2011).

Nesse sentido, além de propor o sumak kansay a partir de suas visões de mundo, o movimento indígena equatoriano propõe outros conceitos, como o Kawsak sacha, a selva viva que engloba todos os seres e elementos que existem dentro da selva, com capacidade de agência. Buscam o seu reconhecimento como categoria para promover a construção do sumak kansay por meio de propostas que valorizam e respeitam os direitos da natureza como princípios fundamentais de todos os seres humanos (GUALINGA, 2020). Portanto, desde esta perspectiva, a vida humana não pode ocorrer separada da natureza, o que passa justamente por considerá-la como um sujeito que possui direitos e capacidades de ação política (SIMBAÑA, 2011).

Neste sentido, a concepção do Kawsak sacha, da selva viva, proveniente do Povo Originário de Sarayaku - da Amazônia equatoriana - propõe que a selva tem vida, assim como os seres humanos, destacando a interconexão entre todos os seres e a necessidade de preservar a natureza. Assim, está associada à ontologia política relacional; à reorientação ontológica não dualista baseada em outras formas de conceber o mundo. Está presente especialmente nas lutas dos povos e nacionalidades indígenas do Equador contra a atuação das empresas transnacionais extrativistas nos seus territórios (ESCOBAR, 2018).

Por isso, destaca-se o caráter da ancestralidade que inspira as lutas atuais do movimento indígena. Segundo essa perspectiva, a exploração do petróleo não é considerada uma ferramenta de desenvolvimento, pois não contribui para o bem-estar social ao gerar grandes impactos socioambientais negativos. Por essa razão, defendem um modelo de desenvolvimento com menor impacto no mundo natural.

Na verdade, é importante destacar as lutas pela construção da autonomia especialmente dos povos e nacionalidades indígenas amazônicos, levando em conta a existência de recursos naturais, como hidrocarbonetos e minerais, mas sobretudo a grande biodiversidade presente na região. Dessa forma, destaca-se a importância do fortalecimento das organizações indígenas nos ecossistemas e regiões-chave, como é justamente o caso da Amazônia, disputando o poder por meio da construção de projetos políticos, econômicos, sociais e epistemológicos com outros atores, inclusive com atores globais, como são as transnacionais que atuam na região.

Menciona-se, portanto, que os direitos da natureza foram reconhecidos e constitucionalizados no caso equatoriano, compreendendo a natureza de acordo com a visão de mundo indígena como o lugar em que a vida é produzida e realizada em toda sua integralidade (SANTOS, 2010b). Portanto, considera-se que o reconhecimento da natureza e da biodiversidade como 
sujeitos de direitos abrem espaços para outros horizontes de desenvolvimento distintos do modelo neoliberal hegemônico e evidenciam mais uma vez a importância do movimento indígena equatoriano como um ator político e epistêmico relevante nas dinâmicas no país.

\section{A modo de conclusão: Construindo a globalização contra-hegemônica}

Consideram-se que os marcos epistemológicos, ontológicos e teóricos propostos, a partir do diálogo entre as Epistemologias do Sul, a ontologia política relacional e o pensamento decolonial latino-americano, e a revisão bibliográfica realizada, são essenciais para compreender e, sobretudo, ressaltar a importância do movimento indígena equatoriano como um ator político e epistêmico de grande relevância para as dinâmicas do país, cujos ideais podem incidir a nível regional.

As alternativas à globalização hegemônica neoliberal desenvolvidas pelos movimentos sociais oferecem alternativas ao capitalismo hegemônico, justamente a partir de outras bases epistêmicas. Estão precisamente associadas ao pensamento crítico e às lutas pela defesa dos territórios e formas de vida, a partir de movimentos sociais contra-hegemônicos, como é o caso do movimento indígena.

Neste sentido, ressaltam-se os seus discursos de construção da plurinacionalidade e da interculturalidade, que, desde a dimensão epistemológica e ontológica, são incompatíveis com o modelo de globalização hegemônica neoliberal, o que os leva a construir, desde distintos modos e níveis, a globalização contra-hegemônica, resgatando os seus sistemas próprios de vida; fortalecendo a geração de conhecimentos próprios; fortalecendo a comunidade desde o âmbito político por meio da democracia comunitária, e também desde o âmbito social e econômico a partir de propostas econômicas alternativas, associadas a outros princípios, como à solidariedade e à complementariedade, em maior harmonia com a natureza, construindo alternativas desde a economia popular.

De fato, predominam os discursos e ações contrários às propostas de avanço do neoliberalismo no país, participando na caída de alguns presidentes, além de conter o avanço destas propostas, o que foi nítido nos acontecimentos de outubro de 2019, em que a CONAIE e toda a sua estrutura, compreendendo as organizações de base, foi um ator imprescindível para aglutinar o descontento de diversos setores sociais, logrando impedir, ainda que temporalmente, a implementação das propostas neoliberais acordadas entre o governo de Lenin Moreno e o Fundo Monetário Internacional.

A soberania, um dos princípios essenciais na filosofia andina e amazônica, transcende a dimensão da soberania comunitária e a autonomia interna dos povos e nacionalidades indígenas do país, passando a integrar as ações que buscam defender a soberania do próprio Estado, rejeitando as formas de sujeição e domínio geradas pelos mecanismos de colonialidade do poder presentes também a nível internacional.

Apesar da introdução de algumas das suas propostas na Constituição de 2008, com a consequente construção formal do Estado plurinacional equatoriano, isso não significa a verdadeira emancipação dos povos e nacionalidades indígenas do país, senão que é um ponto 
importante na continuidade das suas lutas históricas, agora buscando a implementação efetiva desses conceitos, transformados em direitos. Deste modo, ressalta-se a importância das ações políticas e das propostas epistêmicas deste setor que historicamente contribuem aos processos de descolonização nos más diversos níveis, por meio das lutas e resistências políticas, sociais e epistemológicas.

\section{Referências}

ALBÓ, Xavier; BARRIOS SUVELZA, Franz Xavier. Por una Bolivia plurinacional e intercultural con autonomías. La Paz: PNUD, 2007.

BERNAL-MEZA, Raúl. La refundación del estado boliviano: Autonomías, regionalismo y representación internacional. Ciclos En La Historia, La Economía y La Sociedad, v. 47, n. 27, 2016.

CRUZ RODRÍGUEZ, Edwin. Redefiniendo la nación: Luchas indígenas y Estado plurinacional en Ecuador (1880-2008). Nómadas. Revista Crítica de Ciencias Sociales y Jurídicas, núm. Esp.,, p. 01-24, 2012.

CRUZ RODRÍGUEZ, Edwin; GUERRA URREGO, Hugo. El tránsito hacia el Estado plurinacional en Bolivia y Ecuador. Studia historica - Historia contemporánea, v. 28, p. 97124, 2010.

DÁVALOS, Pablo. Movimiento indígena ecuatoriano: Construcción política y epistémica. In: MATO, Daniel (Org.). Estudios y otras prácticas intelectuales latinoamericanas en cultura y poder. [s.l.]: Consejo Latinoamericano de Ciencias Sociales, 2002.

ESCOBAR, Arturo. Designs for the pluriverse: radical interdependence, autonomy, and the making of worlds. Durham: Duke University Press, 2018.

GROSFOGUEL, Ramón. Para descolonizar os estudos de economia política e os estudos pós-coloniais: transmodernidade, pensamento de fronteira e colonialidade global. In: SANTOS, Boaventura de Sousa (Org.). Epistemologias do Sul. Coimbra: Almedina, 2010.

GUALINGA, José. Voices from Amazon: Sarayaku, Amazon Basin, Ecuador. [s.l.: s.n.], 2020. Disponível em: <https://www.facebook.com/voicesfortheplanet/videos/776474232871391/UzpfSTE2NDU4MjY0ODM6MTAyMTY1MTM5NTM1NTUxMDQ/>. Acesso em: 20 maio 2020.

LLASAG, Raúl. Constitucionalismo plurinacional en Ecuador y Bolivia a partir de los sistemas de vida de los pueblos indígenas. 2017. 134f. Tese (Doutorado em Poscolonialismo e Cidadania Global) - Universidad de Coímbra, Coimbra, 2017.

MENESES, Maria Paula; PEIXOTO, Carolina. Boaventura de Souza Santos: Na oficina do sociólogo artesão. Aulas 2011-2016, 2018.

MIGNOLO, Walter. Desobediencia epistémica: retórica de la modernidad, lógica de la colonialidad y gramática de la descolonialidad. [s.l.: s.n.], 2017.

PUEBLO ORIGINARIO KICHWA DE SARAYAKU. Corte Interamericana de Derechos Humanos: Caso Pueblo Indígena Kichwa de Sarayaku Vs. Ecuador - Caso No. 12.465. 2009. Disponível em: <http://www.corteidh.or.cr/docs/casos/sarayaku/esap.pdf>. Acesso em: 20 maio 2020. 
QUIJANO, Aníbal. Colonialidad del poder, eurocentrismo y América Latina. In: LANDER, Edgardo (Org.). La colonialidad del saber: Eurocentrismo y ciencias sociales. Perspectivas Latinoamericanas. Buenos Aires: Consejo Latinoamericano de Ciencias Sociales- , 2000.

SANTOS, Boaventura de Sousa (Org.). Epistemologias do Sul. Coimbra: Almedina, 2010a.

SANTOS, Boaventura de Sousa. Refundación del Estado en América Latina: Perspectivas desde una epistemología del Sur. Quito: Abya-Yala, 2010b.

SILVA JÚNIOR, Gladstone Leonel da. A constituição do Estado plurinacional da Bolívia como um instrumento de hegemonia de um projeto popular na América Latina. 2014. 350f. Tese (Doutorado em Direito) - Universidade de Brasília, Brasília, 2014.

SIMBAÑA, Floresmilo. El sumak kawsay como proyecto político. In: LANG, Miriam; GUDYNAS, Eduardo (Orgs.). Más allá del desarrollo. Quito: Abya Yala, 2011.

SVAMPA, Maristella. Extractivismo neodesarrollista y movimientos sociales: ¿Un giro ecoterritorial hacia nuevas alternativas? In: LANG, Miriam; GUDYNAS, Eduardo (Orgs.). Más allá del desarrollo. Quito: Abya Yala, 2011. 